1 Morris JK, Cook DG. A critical review of the effect of factory closures on health. BrJ Ind Med 1991;48:1-8.

2 Hallsten L. Mental health and unemployment. On health-based selection to work. Arbete och Hälsa 1998:7. (Dissertation in Swedish with English abstract.)

3 Weich S, Lewis G. Poverty, unemployment, and common mental disorders: population based cohort study. BMJ 1998;317:115-9.

4 Elkeles T, Seifert W. Unemployment and health impairments. Eur J Public Health 1993;3:28-37.

5 Jin RL, Shah CH, Svoboda TJ. The impact of unemployment on health: a review of the evidence. Can Med Assoc J 1995;153:529-40.

6 Mathers CD, Schofield DJ. The health consequences of unemployment: the evidence. Med J Aust 1998;168:178-82.

7 Bethune A. Economic activity and mortality of the 1981 census cohort in the OPCS longitudinal study, Popul Trends 1996;83:37-42.

8 Martikainen P, Valkonen T. Excess mortality of unemployed men and women during a period of rapidly increasing unemployment. Lance 1996;348:909-12.

9 Bartley M. Unemployment and ill health: understanding the relationship. JEpidemiol Community Health 1994;48:333-7.

10 Avery AJ, Betts DS, Whittington A, Heron TB, Wilson SH, Reeves JP. The mental and physical health of miners following the 1992 national pit closure programme: a cross sectional survey using general health questionnaire GHQ-12 and short form SF-36. Public Health 1998;112:169-73.

11 Matikainen E, Liira J, Rytkönen H. Health, work ability and working conditions of construction workers. Study design and follow-up in 1991-1995. Tÿ̈ ja ihminen 1998;12:85-93, 152. (In Finnish with English abstract.)

12 S-PLUS 4 guide to statistics. Seattle: Data Analysis Products, Math Soft, 1997.
13 Leino-Arjas P, Liira J, Mutanen P, Malmivaara A, Matikainen E Unemployment, health and health behaviour of construction workers. Työ ja ihminen 1998;12:139-48, 155. (In Finnish with English abstract.)

14 Ryan J, Zwerling C, Jones M. Cigarette smoking at hire as a predictor of employment outcome. J Occup Environ Med 1996;38:928-33.

15 Lee AJ, Crombie IK, Smith WCS, Tunstall-Pedoe HD. Cigarette smoking and employment status. Soc Sci Med 1991;33:1309-12.

16 Dooley D, Catalano R. Unemployment as a stressor: findings and implications of a recent study. In: Badura B, Kickbusch I, eds. Health promotion research. Towards a new social epidemiology. Copenhagen: WHO Regional Publications, 1991:313-39. (European series No 37.)

17 Morris JK, Cook DG, Shaper AG. Non-employment and changes in smoking, drinking, and body weight. BMJ 1992;304:536-41.

18 Janlert U, Hammarström A. Alcohol consumption among unemployed youths: results from a prospective study. Br J Addict 1992;87:703-14.

19 Montgomery SM, Cook DG, Bartley MJ, Wadsworth M. Unemployment, cigarette smoking, alcohol consumption and body weight in young British men. Eur J Publ Health 1998;8:21-7.

20 Liira J, Leino-Arjas P. Unemployment in construction and forest work. Predictors and consequences in a 5-year follow-up. Scand J Work Environ Health 1999;25:42-9.

21 Ezzy D. Unemployment and mental health: a critical review. Soc Sci Med 1993:37:41-52.

22 Lynch JW, Kaplan GA, Shema SJ. Cumulative impact of sustained economic hardship on physical, cognitive, psychological, and social functioning. New Engl J Med 1997;337:1889-95.

(Accepted 2 June 1999)

\title{
Doctors as patients: postal survey examining consultants and general practitioners adherence to guidelines
}

\author{
Malcolm Forsythe, Michael Calnan, Barbara Wall
}

\begin{abstract}
Objectives To examine the adherence by senior NHS medical staff to the BMA guidelines on the ethical responsibilities of doctors towards themselves and their families.

Design Postal semistructured questionnaire.

Setting Four randomly selected NHS trusts and three local medical committees in South Thames region.

Subjects Consultants and principals in general practice.

Main outcome measures Personal use of health services.

Results The response rate was 64\% (724) for general practitioners and $72 \%$ (427) for consultants after three mailings. Most $(1106,96 \%)$ respondents were registered with a general practitioner, although little use was made of their services. 159 (26\%) general practitioners were registered with a general practitioner in their own practice and $80(11 \%)$ admitted to looking after members of their family. 73 (24\%) consultants would never see their general practitioner before obtaining consultant advice. Most consultants and general practitioners admitted to prescribing for themselves and their family. Responses to vignettes for different health problems indicated a general reluctance to take time off, but there were differences between consultants and general practitioners and by sex. Views on improvements needed included the possibility of a "doctor's doctor," access to out of area secondary care, an occupational health service for general practitioners, and regular health check ups.
\end{abstract}

Conclusion The guidelines are largely not being followed, perhaps because of the difficulties of obtaining access to general practitioners outside working hours. The occupational health service should be expanded and a general practitioner service for NHS staff piloted.

\section{Introduction}

Mortality data show that compared with the general male population doctors have a significantly lower mortality ratio, but deaths from specific causes such as suicide and external injury and poisoning are significantly higher. ${ }^{1}$ More recent evidence shows that male doctors (aged 20-74) have a significantly higher proportional mortality ratio for viral hepatitis, liver cancer, and cirrhosis and women doctors (aged 20-74) have a higher ratio for cancer of the pancreas. Research into morbidity is dominated by measuring levels of stress, anxiety, and depression and the possible causes. ${ }^{3-9}$ The picture emerging is of general practitioners and senior hospital doctors with high levels of stress, anxiety, and depression who take very little time off work for illness but who, when they are off work, tend to be off for long periods.

The Nuffield Trust report in 1994 showed serious shortcomings in the services available and the way in which doctors treat themselves and their colleagues. ${ }^{10}$ Recognising this, the BMA produced in 1995 a set of guidelines on the ethical responsibilities of doctors towards themselves and their families and to other doctors as patients. ${ }^{11}$ These have subsequently been endorsed by the Academy of Royal Medical Colleges ${ }^{12}$ and the General Medical Council. ${ }^{13}$ We studied the
Centre for Health Services Studies, George Allen Wing, University of Kent, Canterbury, Kent CT2 7NF

Malcolm Forsythe professorial fellow in public health

Michael Calnan director

Barbara Wall research officer M Forsythe J.M.Forsythe-2@ ukc.ac.uk

BMJ 1999;319:605-8

website

extra

More details of the questions put to participants are available on the $B M J$ 's website

www.bmj.com 
Ethical responsibilities of doctors towards themselves and their families ${ }^{11}$

1. It is not advisable for doctors to assume responsibility for the diagnosis and management of their own health problems or those of their immediate family, except in the most unusual circumstances 2. All doctors should be registered with a general practitioner. All hospitals with resident staff should ensure that staff have access to primary care services. Staff must be given time to attend the doctor's surgery where necessary. The hospital occupational health service will give advice on the preventive measures or surveillance procedures which should be provided to doctors at risk and is the link between the employee's health and the workplace

3 . As with all other patients, the responsibility for overall care and continuity of treatment for doctors and their families should rest with their general practitioner. Referral for consultant advice or care should be made through their general practitioner

4. It is preferable that a doctor's general practitioner should not be a relative nor, if at all feasible, a partner of the doctor

5. It is not advisable for doctors, including professional suppliers, to prescribe themselves anything other than over the counter medicines

6 . Doctors need to be aware that they become the patient in the doctor-patient partnership when they are receiving medical care

7. Doctors have an ethical duty, to themselves and to their patients, to ensure that their own health problems are effectively managed; to seek competent professional advice particularly on their ability to work; and to follow this advice

8. Doctors should not take advantage of the access they have to medical records to look at the records of their family and friends without previous consent

9. Doctors have a responsibility to ensure that they are protected against infectious diseases such as tuberculosis and hepatitis B

10. Doctors should not undermine the confidence that their relatives have in their own general practitioner by disparaging the advice and treatment that they are given

extent to which this guidance is being followed, focusing on the ethical responsibilities outlined in the box.

\section{Participants and methods}

The study was carried out in the South Thames region, which for sampling purposes was stratified into three areas: inner London, outer London, and counties. We selected one acute trust and one local medical committee at random from each area. In addition, a community trust was randomly selected from all the community trusts. Once support was obtained from each of the trusts and local medical committees, we sent questionnaires to all consultants $(n=595)$ and general practitioners $(n=1138)$ in 1997 . Two reminders were sent to non-respondents.

The postal, self completed questionnaires (which had been piloted) consisted of questions exploring adherence to the guidelines-that is, registration with general practitioner, consultation rates, availability and use of occupational health, prescribing habits for self and family; vignettes about possible patterns of action in response to signs, symptoms, and patterns of behaviour which they experienced themselves ${ }^{7}$ and for problems affecting close relatives (see BMJ's website for full details); and sociodemographic and specialty information.

\section{Results}

We received completed questionnaires from 724 (64\%) general practitioners and $427(72 \%)$ consultants. No information is available on the non-respondents.

\section{Registration with general practitioner}

In all, $706(98 \%)$ general practitioners and 400 (94\%) consultants reported that they were registered with general practitioners, although 419 (63\%) general practitioners and $252(59 \%)$ consultants stated they had not consulted their general practitioner within the past 12 months. In all, $159(26 \%$ of those in partnerships) general practitioners were registered with a partner in the same practice. There was a significant difference by sex $\left(\chi^{2}=26.9, \mathrm{P}<0.001\right)$, with about one third of men (122) having a partner in the practice as their general practitioner but only $15 \%$ (37) of women. The proportion of general practitioners who were registered with a partner in their practice increased with age, but this relation was significant only for women. $\left(\chi^{2}=14.2, \mathrm{P}<0.001\right)$.

Only eight $(1 \%)$ general practitioners had a general practitioner who was a relative, although 78 (11\%) did not respond to this question. Eighty (11\%) general practitioners were looking after some members of their family. The older the doctor the more likely they were to be a general practitioner to members of the family, with $14(37 \%)$ of the male respondents over the age 60 being general practitioners to family members (men: $\chi^{2}=39.5, \mathrm{P}<0.001$; women $\left.\chi^{2}=7.5, \mathrm{P}<0.05\right)$.

Respondents were asked whether they would call a general practitioner before obtaining advice from a consultant. After doctors who had never had to seek consultant advice were excluded, 25 (9\%) male general practitioners said they would never consult a general practitioner compared with $10(4 \%)$ female general practitioners; 73 (24\%) consultants indicated they would never see a general practitioner before obtaining consultant advice.

\section{Prescribing}

A total of $505(71 \%)$ general practitioners and 316 $(76 \%)$ consultants responded that they "usually" or "sometimes" self prescribed. Seventy three (10\%) general practitioners and $63(15 \%)$ consultants also admitted usually or sometimes self prescribing opiates, anxiolytics, antidepressants, or hypnotics; 585 (83\%) general practitioners and $282(70 \%)$ consultants prescribed for their family.

\section{Occupational health service}

Only $80(11 \%)$ general practitioners reported that there was an occupational health service available for their use compared with 404 (95\%) consultants. Most consultants $(219,57 \%)$ used the occupational health service mainly for preventative and surveillance procedures. Only 25 consultants had used the service 
to discuss another member of staff's ability to work and seven to discuss their own ability to work.

\section{Attitudes to hypothetical illness}

Respondents were asked a series of hypothetical questions about how they would respond to a range of different signs, symptoms, and behaviour that affected themselves (see $B M /$ s website). They were invited to answer one or more of the following possible actions: consult formally (general practitioner, hospital outpatients, occupational health); consult informally (medical friend or colleague); self treat (prescribe drugs); take time off; and go to work, and wait and see. On average, across all the questions $75 \%$ (320) of consultants and $72 \%$ (513) of general practitioners reported only one course of action.

Table 1 shows that only for vomiting all night would the majority of both general practitioners and consultants go to work. General practitioners were more likely to go to work than consultants. For every question except growing dependency on alcohol general practitioners were more likely to self medicate than consultants, who in turn were more likely to consult informally. Little difference was found between groups in reported formal consultation, and only for blood in urine would a majority of both consultants and general practitioners consult formally. Patterns of consultation differed by sex. Table 2 shows that women were more likely to go to work or self medicate and less likely to consult either informally or formally than their male counterparts. However, female general practitioners were much less likely to consult informally and much more likely to self medicate than female consultants.

Attitudes to use of health care for family illness Respondents were asked their response to three vignettes about how they would deal with illness in the family (see BMJ's website). The response to acute tonsillitis in a child at the weekend varied greatly between the two groups, with 593 (82\%) general practitioners prescribing an antibiotic compared with 172 (40\%) consultants. On the other hand, 179 (42\%) consultants would call out a general practitioner compared with $12(2 \%)$ general practitioners. Eighty eight (12\%) general practitioners and $65(15 \%)$ consultants would advise to wait till Monday. Fifty two (12\%) consultants would advise going to accident and emergency compared with five $(1 \%)$ general practitioners.

In response to a relative with extreme anxiety (heart palpitations, trembling, nausea) because of examinations or interview, $487(67 \%)$ general practitioners and $255(60 \%)$ consultants favoured persuading their relative to visit a general practitioner. More general practitioners would prescribe an anxiolytic than consultants (134 (19\%) v $31(7 \%))$, and more consultants would persuade the relative to be patient and stick it out than general practitioners $(167(39 \%) v 158$ $(22 \%))$.

In the case of sleeplessness in a spouse or relative after a burglary, $244(57 \%)$ consultants favoured the relative visiting a general practitioner compared with $323(45 \%)$ general practitioners. Nearly twice as many general practitioners as consultants would have prescribed a hypnotic $(214(30 \%) v 65(15 \%))$
Table 1 Attitudes to hypothetical illness in themselves among consultants and general practitioners. Values are numbers (percentages) of doctors responding to each question

\begin{tabular}{|c|c|c|c|c|c|}
\hline IIIness & $\begin{array}{l}\text { Go to } \\
\text { work }\end{array}$ & $\begin{array}{c}\text { Take time } \\
\text { off }\end{array}$ & $\begin{array}{c}\text { Self } \\
\text { medicate }\end{array}$ & $\begin{array}{c}\text { Informal } \\
\text { consultation }\end{array}$ & $\begin{array}{c}\text { Formal } \\
\text { consultation }\end{array}$ \\
\hline \multicolumn{6}{|l|}{ Vomiting all night } \\
\hline Consultants & $226(53)$ & $205(48)$ & $85(20)$ & $29(7)$ & $39(9)$ \\
\hline General practitioners & $485(67)$ & $240(33)$ & $212(29)$ & $36(5)$ & $30(4)$ \\
\hline \multicolumn{6}{|l|}{ Blood in urine } \\
\hline Consultants & $114(27)$ & $9(2)$ & $14(3)$ & $145(34)$ & $230(54)$ \\
\hline General practitioners & $266(37)$ & $7(1)$ & $185(26)$ & $89(12)$ & $394(54)$ \\
\hline \multicolumn{6}{|c|}{ Growing dependency on alcohol } \\
\hline Consultants & $87(20)$ & $22(5)$ & $3(1)$ & $154(36)$ & $190(45)$ \\
\hline General practitioners & $204(28)$ & $66(9)$ & $7(1)$ & $216(30)$ & $326(45)$ \\
\hline \multicolumn{6}{|c|}{ Unexplained onset of headaches } \\
\hline Consultants & $114(27)$ & $21(5)$ & $52(12)$ & $158(37)$ & $213(50)$ \\
\hline General practitioners & $346(48)$ & $29(4)$ & $227(31)$ & $104(14)$ & $298(41)$ \\
\hline \multicolumn{6}{|c|}{ Severe anxiety for 2 weeks } \\
\hline Consultants & $110(26)$ & $63(15)$ & $27(6)$ & $143(33)$ & $195(46)$ \\
\hline General practitioners & $264(37)$ & $115(16)$ & $92(13)$ & $153(21)$ & $349(48)$ \\
\hline \multicolumn{6}{|c|}{ Suspected stomach ulcer } \\
\hline Consultants & $85(20)$ & $10(2)$ & $119(28)$ & $132(31)$ & $206(48)$ \\
\hline General practitioners & $199(28)$ & $13(2)$ & $331(46)$ & $55(8)$ & $377(52)$ \\
\hline \multicolumn{6}{|c|}{ Low mood over the past month } \\
\hline Consultants & $137(32)$ & $61(14)$ & $18(4)$ & $122(29)$ & $196(46)$ \\
\hline General practitioners & $286(40)$ & $92(13)$ & $63(9)$ & $150(21)$ & $351(49)$ \\
\hline
\end{tabular}

Table 2 Responses of consultants and general practitioners to combined hypothetical illnesses according to sex. Values are numbers (percentages) of responses to each action

\begin{tabular}{lccccc} 
& \multicolumn{2}{c}{ Consultants } & & \multicolumn{2}{c}{ General practitioners } \\
\cline { 2 - 3 } \cline { 6 - 6 } Action & Men & Women & & Men & Women \\
\hline Go to work & $634(27)$ & $239(36)$ & & $1110(37)$ & $930(47)$ \\
\hline Take time off & $311(13)$ & $80(12)$ & & $360(12)$ & $202(10)$ \\
\hline Self medicate & $218(9)$ & $100(15)$ & & $604(20)$ & $508(25)$ \\
\hline Consult informally & $706(30)$ & $177(27)$ & & $550(18)$ & $253(13)$ \\
\hline Consult formally & $1014(44)$ & $255(38)$ & & $1342(44)$ & $778(39)$ \\
\hline
\end{tabular}

\section{Services available for doctors}

Only 89 (12\%) general practitioners and 33 (8\%) consultants were dissatisfied with the services available in their area for the healthcare needs of doctors. Respondents' suggestions for improvement showed endorsement of the BMA guidelines but with some form of monitoring to ensure compliance. Locum provision, fast tracking, the provision of primary care in hospitals, a general practitioner familiar with doctors' problems, and "out of area" access for specialist care, particularly for psychiatric illness and substance misuse, were all commonly suggested improvements. Many general practitioners expressed a need for an occupational health service. Many consultants and general practitioners recognised that they might need a regular health check.

\section{Discussion}

This study showed a low level of adherence to the BMA guidelines. Most consultants and general practitioners were registered with a general practitioner, and the general practitioner's doctor was rarely a relative. However, consultation rates with their general practitioner for both groups of doctors appeared to be low compared with that of the general population. ${ }^{14}$ Self prescribing was common among both groups of doctors. The "low" consultation rate might be explained by major barriers to seeking formal help, 
provision of a consultant led occupational service to cover all NHS staff may improve compliance.

- Senior doctors are not following the BMA guidelines on looking after their own and their families' health

- They seem very reluctant to consult their general practitioner

- They prefer to self treat, carry on working, and consult informally

- Potential barriers to access should be removed in order to improve their health

including the difficulties in gaining access to their general practitioner.

Another potential barrier is whether the local general practitioner and occupational health service is perceived as the appropriate confidential setting for consultation. This is especially important given the high levels of psychosocial problems and substance misuse experienced by doctors. Our study showed that consultants were reluctant to discuss their health with the occupational health service, and many preferred to bypass their general practitioner. Also, many general practitioners were registered with doctors in the same practice and did not have an occupational health service available even if they wished to use it.

The effect of age on the proportion of general practitioners who are registered in their own practice could be due to a generation or ageing effect. Women were less likely to be registered with a partner in their own practice, had fewer informal and formal consultations, and were more likely to self medicate than men. This might be explained by the pressure on women doctors to be seen to be working at least as hard as men or might reflect the wider sex difference in response to illness. As a whole, general practitioners were more likely to continue to work when ill than consultants, which might reflect the working conditions, nature of work, and workload of the different branches of medicine. General practice is more demand led, and it may be difficult and expensive to find an appropriate replacement or locum.

Self prescribing and prescribing for the family is prevalent, and the reliability of this evidence is confirmed by the responses to the vignettes. Most doctors have access to the full range of drugs and this coupled with medical knowledge is viewed by the Office for National Statistics as contributing towards the high suicide levels of doctors. In practice however, there are currently no mechanisms in place to monitor doctor's self prescribing.

In conclusion, the BMA guidelines on doctors treating themselves and their families are not being followed, although there was support for them. If the profession believes that the guidelines are important for the health of doctors and their families they should be promoted widely and monitored. Our results point to a need for specific measures such as the provision of a dedicated general practitioner service for doctors and their families coupled with an out of area service, particularly for treatment of psychosocial problems and substance misuse. These changes together with
We thank the late Pamela Baldwin and the Well at Work Unit, University of Edinburgh, for the use of the vignettes.

Contributors: MF initiated the study, developed the core ideas, was involved in designing the protocol for submission for funding, supervised the data analysis, and wrote the paper. MC contributed to the development of the protocol, design, and general methodology of the study and was involved in writing the final version. BW was responsible for sampling, data analysis, and overall collection of data and commented on various versions of the article. MF and MC will act as guarantors.

Funding: NHS Executive South Thames, Research and Development Programme.

Competing interests: None declared.

1 Office of Population Censuses and Surveys. Occupational mortality 1979-80, 1982-83. London: HMSO, 1986.

2 Office of Population Censuses and Surveys. Occupational health decennial supplement.London: HMSO, 1995.

3 Sutherland VJ, Cooper CL. Job stress, satisfaction, and mental health among general practitioners before and after the introduction of the new contract. BMJ 1992;304:1545-8.

4 Allen I. Doctors and their careers-a new generation. London: Policy Studies Institute, 1994.

5 Firth-Cozens J. Stress in doctors: a longitudinal study. Leeds: University of Leeds, 1995.

6 Chambers R, Campbell I. Anxiety and depression in general practitioners. Fam Pract 1996;13:170-3.

7 Baldwin PJ, Dodd M, Wrote RW. Young doctors' health-how do working conditions affect attitudes, health and performance. Soc Sci Med 1997:45:35-40.

8 Caplan RP. Stress, anxiety, and depression in hospital consultants, general practitioners, and senior health service managers. BMJ 1994;309:1261-3.

9 McKevitt C, Morgan M, Simpson J, Holland WW. Doctors'health and needs for services. London: Nuffield Trust, 1995.

10 Sylvester S, Allen H, Withey C, Morgan M, Holland WW. The provision of medical services to sick doctors. A conspiracy of friendliness? London: Nuffield Trust, 1994.

11 British Medical Association. Ethical responsibilities involved in treating doctor-patients. London: BMA, 1995.

12 Academy of Royal Medical Colleges. Report of a working party. London: ARMC, 1998.

13 Doctors should not treat themselves or their families. GMC News 1998;3:5.

14 Office of Population Censuses and Surveys. Fourth national study of morbidity statistics from general practice, 1991/2. London, HMSO, 1992.

(Accepted 26 May 1999)

\section{Corrections and clarifications}

Food production and safety

In this article by T A B Sanders (19 June, pp 1689-93) the text should have made clear that fluoroquinolones are not authorised as growth promoters in the European Union.

Mercury poisoning after spillage at home from a sphygmomanometer on loan from hospital

In this "Lesson of the week" by C Rennie and colleagues (7 August, pp 366-7), "serum mercury concentrations" should have read "whole blood mercury concentrations" throughout; in the table "creatine" should have read "creatinine."

In screening for congenital cataract, many false referrals will occur

The authorship of this letter (10 July, p 122) was wrongly attributed to Stephen Morgan only; Nigel Hall, a specialist registrar in ophthalmology and a Wellcome Trust fellow, should also have been acknowledged as an author (his address is the Medical Research Council Environmental Epidemiology Unit, University of Southampton, Southampton General Hospital, Southampton SO16 6YD) 